\title{
The Practice of Adapted Wushu in Brazil
}

\author{
Marcelo Moreira Antunes ${ }^{1}$, José Júlio Gavião De Almeida ${ }^{2}$ \\ ${ }^{I}$ PhD in Physical Education from State University of Campinas. Professor of the State University of Rio de \\ Janeiro. \\ ${ }^{2} P h D$ in Physical Education from State University of Campinas. Professor of the State University of Campinas.
}

\begin{abstract}
The aim of this study is to conduct a survey of the practice of wushu by people with different impairments in academies, associations and federations in Brazil. Twenty one states affiliated to the Brazilian Wushu Kung fu Confederation (BWKC) took part in this study, filling out a questionnaire with qualitative information of the wushu practice by disabled people. Twenty one states affiliated to the BWKC took part in this study, twelve of which presented occurrence of wushu practice by disabled people, representing $57.1 \%$. From a total of thirty two practitioners with disabilities identified in Brazil, the great majority are physical impairment practitioners (40.6\%), followed by practitioners with hearing impairment (34.4\%), intellectual impairment (18.7\%) and those with visual impairment (6.3\%). The practice of wushu in Brazil by disabled people is an indicator that martial arts can be practiced by this public, providing the training programs are adjusted to meet different demands.
\end{abstract}

Keywords: Wushu. Martial arts for disability people. Kungfu. Impairment. Adapted Sport.

\section{Background And Study Aim}

Despite of the exponential growth in development on adapted sports after the Second World War, many activities had already been created for people with disabilities. Martial arts may be included as one those activities, it is due to results of several wars that occurred along the history, one of its consequences were always countless injured war people. However, some of them might have still performed a function in the battlefield. Thus, it was necessary making some adaptations to their new conditions in order to allow them to carry out their active duty.

In China, it was no different. Various wars were promoted to conquer territories, bring governments down and defend regions against foreign invasions ${ }^{1}$. In this process every civil and military force were constituted as fundamental to achieving these goals, also including people with disabilities. It can be verified since antiquity that many disabled people took part in battlefields. In Wushu this can be found in some styles like Hung Gar which has standardized training for upper limb amputees. Or, the dialogue of a blind master teaching his pupil the basis of the philosophy of the practice of Wushu².

Nevertheless, in the nineteenth century is that Wushu started a further transformation that allowed the participation of disabled people in their practice. The focus on health promotion and social integration started by this time guiding the development of Wushu in China since the foundation of Jingwu in $1909^{3}$. In this regard, the practice of Wushu by disabled people is also contemplated.

Since 1949 China had undergone profound political, social and culture transformations, led by the establishment of communism as a political ideology and the founding of the People's Republic of China ${ }^{4}$. Therefore, Wushu was influenced by these changes, becoming a sport widely practiced by the population in order to be an Olympic sport in the future.

In order to broaden the scope of practice Wushu, especially by disabled people, some systematic initiatives have been developed in China and elsewhere. An example of this is the systematic development of Taijiquan applied to people with physical disabilities who use wheelchairs to get around. This system consists of application of Taichichuan in wheelchairs with physical disabilities ${ }^{5}$. This modality was formally presented at the opening of the Beijing Paralympic Games in 2008 as a demonstration sport.

The present work aims to identify the practice of Wushu by disabled people in this context of increasing opportunities for the practice by disabled people in Brazil. It was intended to conduct a survey of the practice of Wushu by people with different impairments in academies, associations and federations in Wushu in Brazil.

\section{Material And Methods}

The informants selected for this study were the twenty one presidents of the federations affiliated to CBKW who answered a questionnaire during XX Brazilian Wushu Kung fu held in 2011, in Brasilia, Federal District, Brazil. The questionnaire consists of three parts; the first part contains identification data to the federation respondent. The second and third part constitute of two tables with information about people with 
disability. The first table refers to practitioners linked to state federations and the second table refers to practitioners not affiliated with these entities. Disabilities were classified as follows: Visual impairment, hearing impairment, physical impairment and mental impairment ${ }^{6}$.

Each term was presented on the instrument with a specific concept for each of them to inform the respondent what was meant by each term. It was described as follows: Visual Impairment - is characterized by partial or total loss of eyesight in both eyes, causing the individual to a limitation in their usual performance. The mere use of glasses or contact lenses is not sufficient to characterize visual impairment. Hearing impairment - is characterized as a total or partial loss of ability to hear or perceive sound signals. It also interferes in the ability of speech and therefore in interpersonal communication. Mental impairment - is a significantly below average intellectual functioning. This disability is also characterized by an inadequate adaptive behavior that it can manifest itself until eighteen years of age. Physical impairment - can be understood as the total or partial loss of motor skills, or by spinal cord injuries, amputations or due to all of upper or lower extremities (arms or legs).

The tables were filled in by informants according to the deficiency, the known number of practitioners and further separated by gender. Thus, we collected data on numbers of practitioners of Wushu in Brazil, classified by disability, gender and state.

It should be noticed that this study was submitted to the Ethics Committee of the Faculty of Medical Sciences, State University of Campinas, receiving a favorable opinion under number 753/2010, CAAE: 0587.0.146.000-10.

\section{Results}

Twenty one states affiliated to the Brazilian Wushu Kung fu Confederation took part in this study, twelve of which presented occurrence of wushu practice by disabled people, representing $57.1 \%$ of the states where is developed wushu practice. This data represents a significant amount of wushu practice by disabled people in Brazil.

Overall, the wushu practitioners with disabilities are characterized predominantly with physical impairment $(40.6 \%)$, followed by practitioners with hearing impairment $(34.4 \%)$, intellectual impairment $(18.7 \%)$ and those with visual impairment $(6.3 \%)$ ), from a total of thirty two practitioners with disabilities identified in Brazil. According to data from 2006, there are 230,000 practitioners of Wushu in Brazil, between affiliated and non-affiliated state federations ${ }^{7}$.

When data are separated by the number of practitioners with disabilities between affiliated and nonaffiliated, we have the following data shown according to Table 1.

Table 1: Wushu practitioners with disabilities in Brazil, according to affiliation of federation states.

\begin{tabular}{|c|c|c|c|c|}
\hline \multirow[b]{2}{*}{ Impairments } & \multicolumn{4}{|c|}{ Occurrence } \\
\hline & Affiliated & Non-Affiliated & Total & $(\%)$ \\
\hline Physical Impairment & 11 & 06 & 17 & 34.7 \\
\hline Hearing Impairment & 07 & 08 & 15 & 30.6 \\
\hline Mental Impairment & 06 & 08 & 14 & 28.6 \\
\hline Visual Impairment & 01 & 02 & 03 & 6.1 \\
\hline Total & 25 & 24 & 49 & 100 \\
\hline
\end{tabular}

The distribution of occurrences Wushu practitioners with disability in relation to gender is presented in Table 2.

Table 2: Distribution of occurrences of Wushu practitioners with disabilities according to gender.

\begin{tabular}{|l|l|l|}
\hline \multirow{2}{*}{ Impairments } & \multicolumn{2}{|l|}{ Occurrence } \\
\cline { 2 - 3 } & Men & Women \\
\hline Physical Impairment & 13 & 04 \\
\hline Hearing Impairment & 08 & 07 \\
\hline Mental Impairment & 10 & 04 \\
\hline Visual Impairment & 03 & 0 \\
\hline Total & $\mathbf{3 4}$ & $\mathbf{1 5}$ \\
\hline
\end{tabular}

Table 2 presents the prevalence of men with disabilities practicing Wushu (69.2\%) and women representing the minority $(30.1 \%)$.

Regarding the distribution of occurrences federative units of Brazil the data show a heterogeneous distribution as shown by Table 3 below. 
Table 3: Distribution of occurrences of wushu practitioners with disabilities by federal units in Brazil.

\begin{tabular}{|c|c|c|c|c|c|c|c|c|c|c|c|c|}
\hline \multirow[t]{2}{*}{ Impairments } & \multicolumn{12}{|c|}{ Occurrence per State } \\
\hline & $\mathbf{C E}$ & RO & $\mathbf{A C}$ & SP & $\mathbf{R S}$ & $\mathbf{R J}$ & GO & MS & ES & PB & PA & PR \\
\hline $\begin{array}{l}\text { Physical } \\
\text { Impairment }\end{array}$ & 6 & 3 & 3 & 1 & 1 & 1 & 2 & 2 & 0 & 0 & 1 & 0 \\
\hline Hearing Impairment & 3 & 3 & 5 & 1 & 0 & 1 & 0 & 0 & 1 & 0 & 0 & 1 \\
\hline Mental Impairment & 2 & 1 & 0 & 3 & 1 & 1 & 0 & 0 & 1 & 0 & 0 & 0 \\
\hline Visual Impairment & 1 & 1 & 0 & 0 & 1 & 0 & 0 & 0 & 0 & 2 & 0 & 0 \\
\hline Total & 12 & 8 & 8 & 5 & 3 & 3 & 2 & 2 & 2 & 2 & 1 & 1 \\
\hline
\end{tabular}

According to Table 3, the states that have a greater number of occurrences of wushu practitioners with a disability were Ceará (CE) with 24.5\%, Roraima (RO) and Acre (AC) with $16.3 \%$, São Paulo (SP) $10.2 \%$, followed by Rio Grande do Sul (RS) and Rio de Janeiro (RJ) both with 6.1\%. In fifth place come the states Goiás (GO), Mato Grosso do Sul (MS), Espírito Santo (ES) and Paraíba (PB) each with 4.1\%. In last place was the state of Pará (PA) and Paraná (PR) each with $2.0 \%$.

\section{Discussion}

The data presented indicate a official practice by people with disabilities in some states of Brazil, however, only twelve out of twenty one states are affiliated to CBKW. Therefore $57.1 \%$ of the states are really identified as officially affiliated. It is said that the practice is official if the data provided by the presidents of official entities in their home states is identified as such. These bodies, known as federations, belong to a sporting system coordinates by CBKW, recognized by the federal government and linked to Brazilian Olympic Committee. Thus the data are official at national level.

These data indicate the prevalence of the practice of Wushu by people with physical disabilities, followed by people with hearing impairment. People with intellectual disability is presented as a third place in the practice of wushu, and those with visual impairments are the least practice this sport. According to the 2010 Population Census conducted by the Brazilian Institute of Geography and Statistics ${ }^{8}$ indicated that $23.9 \%$ of the population have a disability, and of these there is the occurrence of $58.3 \%$ of visual impairment, $21.6 \%$ of physical impairment, hearing impairment of $15.8 \%$ and only $4.3 \%$ of intellectual disability.

Visual impairment is the most common type of disability in Brazil following by physical impairment, however the visually impaired are the smallest number of wushu practitioners and the majority of occurrence among disabled practitioners are physically impaired. Hearing impairment is the third type of disability most common in statistics of Brazil, however, occupy the second position with regard to the practice of wushu in Brazil. Intellectually disabled are the least occurring in Brazil ${ }^{8}$, which is supported by data obtained from the federations that indicate these practitioners occupy the last position in the occurrences.

The occurrence of wushu practice in Brazil by people with a disability is an indicator that martial arts might be practiced by this public, providing the training programs are adjusted to meet different demands. The combat sports can be practiced by people with disabilities if they made minor changes in rules and equipment to be used. The practice of martial arts by people with a disability promotes a sense of improved energy, mental power and concentration, reducing stress and even depression ${ }^{9}$.

Effects of practice are also identified in children with epilepsy with regard to self-concept and promote the quality of life ${ }^{10}$. The practice of martial arts by people with a disability provides the improvement of functional limitations, self-esteem and quality of life ${ }^{11}$. Thus, the practice of wushu by people with a disability in Brazil, not only shows that is possible and an unexplored field, but also enhances quality of life and health of their practitioners.

\section{Conclusion}

Some studies have indicated a relationship between the possibility of combat sports by people with disabilities and benefits offered to those practitioners.

Organize and publicize such studies, as well as encourage further discussion on this current social phenomenon, that is, the entry increasingly effective of people with disabilities in different spheres of activities related to motor sport environment and its varied forms of manifestation is preeminent.

Wushu is not yet an Olympic or Paralympic sport, but reserves a significant dimension in national and international levels and fosters an ever increasing development of participation in sport, including people with disabilities. This can be verified by the number of federations, which identified the practice of wushu for people with disabilities. The analysis demonstrated the prevalence of practicing wushu for people with physical disabilities $(37.4 \%)$, followed by hearing impairment $(30.6 \%)$, intellectual impairment $(28.6 \%)$ and visual impairment (6.1\%). 
This study points us to two delicate phenomena that relate to the sports world: The first stresses the extent that are related to the potential of people with disabilities compared to their desires, challenges and possibilities explored by them, and acceptance of social and cultural transformations and spaces that create trust in order to occur common actions. The second phenomenon revealed by the studies that we started, points to a new concept of combat sports (Fighting or Martial Arts), which is now considered as an educational and sports training that transcends its original concepts, these concepts current in turn suitable to the wishes of a contemporary society.

\section{References}

[1]. Roberts JAG, A concise history of China. Massachusetts: Harvard; 1999.

[2]. Chow D, Spangler R. KUNGFU: History, philosophy and technique. Burbank, CA, USA: Unique Publications; 1982.

[3]. Kennedy LB, Guo ENJ. JINGWU: The school that transformed kung fu. Berkley, CA, USA: Blue Snake Books; 2010.

[4]. Hong F. Women's sports in the People's Republic of China: body, politics and unfinished revolution. In: Hartmann-Tews I, Pfister G. editors. Sport and Women: social issues in international perspective. London/New York: Routledge; 2003. p. $224-37$.

[5]. Guo ZB, Zang YY. Dancing in the Wheelchair Taijiquan for people with ambulatory impairment. Int J disabil Community Rehabil, 2010;9(1), ISSN: 1703-3381.

[6]. Gorgatti MG, Costa RF. Atividade física adaptada: qualidade de vida para pessoas com necessidades especiais. 2ed. Barueri: Manole; 2008

[7]. Blaser MN, Silva LCN, Marrera, A. Kung Fu - Wushu. In: DaCosta, L. organizer. Atlas do esporte no Brasil. Rio de Janeiro: CONFEF; 2006

[8]. IBGE. Instituto Brasileiro de Geografia e Estatística. Censo Demográfico 2010. [Cited: 2013 nov 15]; 1(1). Available From: <http://www.censo2010.ibge.gov.br/>

[9]. Kasum G, Strašo G, Nastasić-Stosković T. Combat sports for persons with disabilities. Physical Culture, 2011;65(1):60-9.

[10]. Conant K, Morgan A, Muzykewicz, D, Clark D, Thiele, E. (2008) A karate program for improving self-concept and quality of life in childhood epilepsy: Results of a pilot study. Epilepsy \& Behavior, 2008;12(1):61-65.

[11]. Martin RA. The physical and psychological benefits of martial arts training for individuals with disabilities. Unpublished master's thesis, University of Wisconsin-Stout, United States, 2002. Available from URL: http://www2.uwstout.edu/content/lib/thesis/2002/2002martinr.pdf. 